American Journal of Agricultural and Biological Sciences 5 (3): 376-379, 2010

ISSN 1557-4989

(C) 2010 Science Publications

\title{
Importance of Program Development Competencies for Agricultural Extension Agents' Performance in Process of Technology Transfer
}

\author{
Neda Tiraieyari, Khairuddin Idris, Azimi Hamzah and Jegak Uli \\ Institute for Social Science Studies, University Putra Malaysia, \\ 43400, Serdang, Selangor, Malaysia
}

\begin{abstract}
Problem statement: The movement of technology from lab to the field has been a challenge for agricultural extension agents. In this study researchers focused on program development competencies for agricultural extension agents in process of technology transfer and discuss the importance of these competencies by determining the relationship between these competencies and performance of extension agents. Approach: The study employed stratified random sampling technique. The sample consisted of 210 extension agents in four states of Malaysia. The data were analyzed using descriptive statistics, Pearson correlation and multiple regression analysis. Results: Extension agents perceived themselves competent in developing program planning, program implementation and program evaluation. The findings supported the positive relationship between competencies and extension agents' performance. Therefore hypothesis of the study was supported. The results of multiple regressions showed program development competencies explained 0.448 of variance of extension agents' performance. Conclusion/Recommendations: It can be concluded that performance of extension agents is expected to increase if they have program development competencies. Results supported the importance of these competencies for performance of extension agents in process of technology transfer. Hence to keep extension agents competent and to further improve their performance, these competencies must be considered and upgraded. Continuous assessment of extension agents' competencies and performance is recommended.
\end{abstract}

Key words: Program development, competency, performance, agricultural extension agent

\section{INTRODUCTION}

Technology transfer is the application of information into use (Rogers, 1995). A text book definition (Soeder et al., 1990) of technology transfer is the managed process of conveying a technology from one party to its adoption by another party. This definition describes technology transfer as a process (Kremic, 2003). Technology transfer is clearly a mission and training certainly is an integral part of technology transfer.

Agricultural extension education is about putting useful knowledge to study. Blackburn and Flaherty (1994) argued that often putting useful knowledge to study means transferring technology which they define as the transfer and spread of technology and technical information or know-how from information sources or developers through those who communicate it to those who receive it. In agricultural extension education, technology transfer is an educational process orchestrated by extension agents through both formal and informal means. The movement of technology from the lab to the field has been a significant challenge for extension agents. In this study researcher focus on program development competencies for extension agents in process of technology transfer and discuss the relationship between these competencies and performance of extension agents.

Program development is a deliberate process through which extension agents are involved in designing, implementing and evaluating educational programs that address needs they identify. Extension agents therefore must be able to develop effective extension programs in process of technology transfer. Development of agricultural extension programs is continues and interrelated series of process. McCaslin and Tibezinda (1997) stated program development is an ongoing process of assessing farmers needs, includes selecting appropriate content and methods in programming delivery, managing program delivery and

Corresponding Author: Neda Tiraieyari, Institute for Social Science Studies, University Putra Malaysia, 43400, Serdang, Selangor, Malaysia 
evaluating program process and outcomes. Similarly Gibson (2001) contented that program development is an ongoing process that extension agents plan, implement and evaluate their educational programs. He mentioned that program development involves three steps: planning a program, implementing the plan and evaluating outputs, outcomes and impacts. Most program developing models are similar in that they divide the program development process into three phases (1) program planning, (2) implementation and (3) evaluation and accountability (Rennekamp, 1999). Hence Program development enables extension agents to plan, implement and evaluate educational programs in process of agricultural technology transfer. Therefore all extension agents must be able to plan, implement and evaluate extension programs while transferring a new technology to the farmers. There is no doubt that program development competency is necessary for extension agents. They must have enough knowledge and skill to plan, implement and evaluate extension program. Since in most of models, program development is a systematic process of planning, implementing and evaluating, in this study the researcher also divided program development competency into three major sub competencies which include program planning, program implementation and program evaluation and examine the relationship between these competencies with extension agents' performance. According to Heffernan and Flood (2000) there is a positive relationship between competencies and performance. Linders (2001) reported that performance and extension competencies are positively related. Similarly Armstrong (2006) sated that competencies are factors that contribute to high levels of individual and organizational performance. In relationship between program development competency and extension agents' job performance, Thach (2008) reported there is a moderate positive relationship between performance of Vietnam extension agents and their program development competency. Correspondently study conducted by Khalil et al. (2008) in Yemen revealed that a moderate positive relationship between extension agents' job performance and their program development competency. In these two study program development competency divide into three major sub competency which include program planning, program implement and program evaluation. Khalil et al. (2008) reported that program evaluation is one of the predictors of agricultural extension agents' job performance.

This study hypothesizes that program development competencies are positively correlated to extension agents' performance.
The specific objectives of the study were to:

- Determine the level of program development competencies of extension agents

- Determine the relationships between program development competencies and extension agents' performance

- Determine those competencies that predict extension agents' performance

\section{MATERIALS AND METHODS}

The study is a descriptive correlation. A structured research instrument was utilized to survey a sample of 210 extension agents from department of agriculture in Malaysia. This study employed a geographical stratified sampling method. The instrument sought the selfreported levels of variables of the study. Pearson correlation was employed to analyze the relationships between the independent variables and dependent variable. Enter method regression was employed to determine to what extent program development competencies explain the variation of performance among extension agents. The dependent variable for this study is extension agents' performance. The extension agents' performance scores consist of eleven dimensions of performance. The composite scores were computed by adding the responses of 46 items used in this study. There are three independent variables namely program planning competency, program implementation competency and program evaluation competency which may have relationship and determine extension agents' performance. The program planning competency was measured by five items indicating the extent of extension agents' ability to plan extension program in the process of technology transfer such as ability to gather data, analysis situation, identify problem and setting objectives. The program implementation competency was measured using four items representing the extent of extension agents' ability to implement activities which are geared towards solving the identified problems. The program evaluation competency comprises eleven items quantifying the extent of extension agents' ability to determine the value or amount of success in achieving predetermined objectives of technology transfer. Validity of Instrument conducted and changes were made to the competencies and performance variable to improve its validity. Results of reliability statistics (Cronbach's Alpha) for each variable were above 0.80.

\section{RESULTS AND DISCUSSION}

The first objective of this study was to determine the level of competency of extension agents on program planning, program implementation and program evaluation. 
Level of competency of extension agents on program planning: Findings indicated mean rating of 7.19 for program planning competency with the minimum rating of 4.40 and a maximum of 10.00 and this gives a range of 5.60. The median program planning skill rating value was 7.00 with a standard deviation of 1.11. (59.5\%) of extension agents rated high level of this competency. (29.5\%) very high and $(11.0 \%)$ moderate.

Level of competency of extension agents on program implementation: The minimum rating for this competency was 2.00 and a maximum of 10.00 and that gave a range of 8.00. The median value was 7.12 with a standard deviation of 1.31 . The mean rating was 7.12. Agricultural extension agents have rated high in justifying this skill. Extension agents who felt that their level of this competency is high (52.8\%), very high $(31.0 \%)$, moderate $(15.2 \%)$ and low $(1.0 \%)$.

Level of competency of extension agents on program evaluation: Results showed the mean rating of 6.81 for this competency with the minimum rating of 3.82 and a maximum of 10.00 and this gives a range of 6.18. The median program evaluation skill rating value was 6.72 with a standard deviation of 1.12. Extension agents have rated high in explaining their program evaluation skill. (66.7\%) of extension agents rated possess the high level of this skill, (15.2\%) very high and $(17.1 \%)$ moderate and 1.0 (low).

Relationship between program development competencies and performance: The second objective of this study was to determine relationships between program development competencies and extension agents' performance. The Pearson correlation coefficient was employed to achieve this objective. As depicted in Table 1 performance is positively related to Program planning competency $(r=0.586, p=0.001)$, Program implementation competency $(r=0.528, p=$ $0.001)$ and Program evaluation competency $(\mathrm{r}=$ $0.653, p=0.001)$. Hence the relationship between all competencies and performance are significant and positive. As a result, the hypotheses are supported. Program planning competency, program implementation competency and program evaluation competency show the large correlation with job performance of extension agents.

The third objective of this study was to identify the predictors for extension agents' performance. To gain a better understanding of program development competencies that influence or help to explain extension agents' performances, Multiple Linear Regressions (MLR) model was proposed to explain the variation of performance among agricultural extension agents.
The equation proposed multiple linear regression models is as follows:

$\mathrm{Y}=3.301+0.203\left(\mathrm{X}_{1}\right)+-0.054\left(\mathrm{X}_{2}\right)+0.438\left(\mathrm{X}_{3}\right)+\mathrm{e}$

$\mathrm{Y}=$ Extension agents' performance

$\mathrm{b}_{0}=$ Constant (intercept)

$\mathrm{X}_{1}=$ Program planning competency

$\mathrm{X}_{2}=$ Program implementation competency

$\mathrm{X}_{3}=$ Program evaluation competency

$\mathrm{e}=$ Error

Based on the method used, only two predictor variables were found to be significant in explaining performance of extension agents. The two predictor variables were program planning competency $(\mathrm{t}=2.849$, $\mathrm{p}=0.005)$ and program evaluation competency $(\mathrm{t}=$ 5.807, $\mathrm{p}=0.000$ ). As illustrated in Table 2, the largest Beta coefficient is 0.526 which is for program evaluation competency. This means that this competency makes the strongest unique contribution to explaining performance of extension agents, when the variance explained by other predictors in the model is controlled. It suggests that one standard deviation increase in program evaluation competency lead to 0.526 standard deviation increase in performance. The Beta value for program planning competency 0.248 is the second highest. Nevertheless the program implementation competency is not significant in explaining extension agents' performance. The findings suggest that the data dose not fully support the proposed three-predictors multiple linear regression model. The $\mathrm{R}^{2}$ value of 0.448 implies that the three predictors explain about $44.8 \%$ of the variance/variation in extension agents' performance or $44.4 \%$ of the variability of agricultural extension agents' performance is accounted for by the competencies in the model.

Table 1: Pearson correlation coefficients of the independent variables and dependent variable

\begin{tabular}{lllll}
\hline Variables & $\mathrm{Y}$ & $\mathrm{X}_{1}$ & $\mathrm{X}_{2}$ & $\mathrm{X}_{3}$ \\
\hline Performance & 1.000 & & & \\
Program planning & 0.586 & 1.000 & & \\
Program implementation & 0.528 & 0.553 & 1.000 & \\
Program evaluation & 0.653 & 0.636 & 0.631 & 1.00 \\
\hline * Significant at 0.05 levels & & & &
\end{tabular}

*Significant at 0.05 levels

Table 2: Estimates of coefficients for the regression model

\begin{tabular}{|c|c|c|c|c|c|}
\hline \multirow[b]{2}{*}{ Model } & \multicolumn{2}{|c|}{$\begin{array}{l}\text { Unstandardized } \\
\text { coefficients }\end{array}$} & \multirow{2}{*}{$\begin{array}{l}\text { Standardized } \\
\text { coefficients } \\
\text { Beta }\end{array}$} & \multirow{2}{*}{$\begin{array}{l}\mathrm{t} \\
\mathrm{B}\end{array}$} & \multirow{2}{*}{$\begin{array}{l}\text { Sig. } \\
\text { Std. erro }\end{array}$} \\
\hline & B & Std. error & & & \\
\hline 1 (Constant) & 3.301 & 0.323 & & 10.206 & 0.000 \\
\hline MF1F5 & 0.203 & 0.071 & 0.248 & 2.849 & 0.005 \\
\hline MG1G4 & -0.054 & 0.066 & -0.076 & -0.820 & 0.413 \\
\hline MH1H11 & 0.438 & 0.075 & 0.526 & 5.807 & 0.000 \\
\hline
\end{tabular}




\section{CONCLUSION}

Extension agents perceived themselves competent in program planning, program implementation and program evaluation. According to correlation analysis program development competencies were found to have correlated with extension agents' performance. Hence extension agents' performance is expected to increase if they have program planning competency, program implementation competency and program evaluation competency. In this study, two program development competencies influencing extension agents' performance. They are program evaluation competency and program planning competency; however in this study program implementation competency didn't influence extension agents' performance. It can be concluded that this results support the importance of these competencies for agricultural extension agents that ensure performance. Hence to improve the performance of agricultural extension agents these competencies must be considered and upgraded. The correlations presented in this study provide the evidence to support a competency model for extension agents include three main category of program development competency. In this study, the results showed that program evaluation competency has the highest contribution to the performance of the extension agents. This finding confirms the results of previous research conducted by Khalil et al. (2008) that this competency predicts extension agents' performance. Focused attention on program development competencies must be paid in order to keep agricultural extension agents competent. It is recommended that the department of agriculture undertake a training program to further improve extension agents' competency and performance.

\section{ACKNOWLEDGEMENT}

We would like to thank the head of Institute for Social Science Studies, University Putra Malaysia that has provided financial support to publish these results in this journal.

\section{REFERENCES}

Armstrong, M., 2006. A Hand Book of Human Resource Management Practices. 10th Edn., Kogan Page, London, ISBN: 10: 0749446315, pp: 982.

Blackburn, D.J. and J. Flaherty, 1994. Historical Roots. In: Extension Handbook, Processes and Practices, Blackburn, D.J. (Ed). Thompson Educational Publishing Incorporated, Toronto, ISBN: 10: 1550770527, pp: 56-67.
Gibson, T.L., 2001. Cooperative extension program planning. University of Wisconsin-Extension Program Development and Evaluation. Program Development and Evaluation. http://www.uwex.edu/ces/pdande/planning/pdf/Pro gramPlanning.pdf

Heffernan, M. and P. Flood, 2000. An exploration of the relationship between the adoption of managerial competencies, organization characteristics human resource sophistication performance Irish organization. J. Eur. Ind., 24:128-136. DOI: 10.1108/03090590010321098

Khalil, A.H.O., M. Ismail, T. Suandi and D.D. Silong, 2008. Extension worker as a leader to farmers: Influence of extension leadership competencies and organizational Commitment on extension workers' performance in Yemen. J. Int. Soc. R., 1/4: 368-387. http://www.sosyalarastirmalar.com/cilt1/sayi4/sayi 4pdf/khalil_and_vd.pdf

Kremic, T., 2003. Technology transfer: A contextual approach. J. Technol. Trans., 28: 149-158.

Linders, J.R., 2001. Competency assessment and human resource management performance of county extension chairs in Ohio. J. Agric. Educ., 42: 21-31. http://pubs.aged.tamu.edu/jae/pdf/Vol42/42-0421.pdf

McCaslin, N.L. and J.P. Tibezinda, 1997. Improving agricultural extension. A reference manual. FAO.

Rennekamp, R.A., 1999. Planning for performance: Developing programs that produce results. Cooperative Extension Service. http://www.ca.uky.edu/agpsd/plan1.pdf

Rogers, E.M. 1995. Diffusion of Innovations. 4th Edn., Free Press, New York, ISBN: 13: 9780029266717, pp: 518.

Soeder, W.E., A.S. Nashar and V. Padmanabhan, 1990. A guide to the best technology-transfer practices. J. Technol. Trans., 15: 5-21. DOI: 10.1007/BF02377652

Thach, L.N., 2008. Individual factors as predictors of extension agents performance in Mekong delta. Ph.D. Thesis, University Putra Malaysia. http://psasir.upm.edu.my/4871/ 